\title{
INNOVATIVE FINANCIAL CRITERIA FOR METHODOLOGICAL APPROACHES TO THE ASSESSMENT OF AGRARIAN INSURANCE
}

\author{
Yuliia Aleskerova ${ }^{1}$, Liubov Kovalenko², Vita Havryliuk ${ }^{3}$
}

\begin{abstract}
The purpose of this article is to study the experience of financial support of agricultural insurance system of Ukraine. Investigated peculiarities of innovative financial criteria of methodological approaches to the estimation of agrarian insurance methodical provision of process and technologies of agricultural insurance are evaluated. The content and principles of functioning of the mechanism of agricultural insurance are revealed. Methodology. The methodical approaches for determining the target indicators of a comprehensive assessment of the development of the agricultural insurance system and its criterion characteristics are developed. Agricultural insurance is considered an area of insurance that is technically demanding. The state is considered and trends and regularities of insurance development are revealed. An assessment of the suitability of any agricultural insurance service should take into account the production system; asset type; key risk factors that are subject to insurance; location of agricultural land; data availability; the size of the farm; sales channels. The research was based on the use of a systematic approach to the consideration of financial phenomena, on the fundamental positions of economic theory, system theory, the theory of finance, insurance management, etc. The quality in the hypostasis of the philosophical category characterizes the stable property of the phenomenon in the dynamics of its general development. Results. The practice and peculiarities of insurance protection of agricultural commodity producers are traced. The advantages and disadvantages of an assortment of insurance products are determined. The main internal and external factors influencing the mechanism of agricultural insurance have been identified. Practical implications. Deepened scientific ideas about the formation of the insurance policy. Unification is carried out according to different algorithms. This is due to the expediency of unifying the components for which the ranking is from the highest to the lowest. Value/originality. The essence of state support of agricultural insurance is determined. Innovative tariff policy is proposed and possibilities of application of non-traditional agricultural insurance products are revealed. The recommendations for determining the main landmarks and the dominant components of the development of agricultural insurance system development strategies have been formed. The conceptual platform for harmonization of the mechanism of agricultural insurance and improvement of its institutional and infrastructural component is substantiated.
\end{abstract}

Key words: agricultural insurance, socio-psychological concept, development, financial, relations, innovation, investment, processes, analyse.

JEL Classification: O31, G22, J43, Q14

\section{Introduction}

The fundamental transformations in the agricultural insurance system conditioned by qualitatively new economic conditions limited the binding nature of insurance protection methods, which were constantly used as state levers of influence on agriculture.

\footnotetext{
Corresponding author:

${ }^{1}$ Vinnytsia National Agrarian University, Ukraine.

ORCID: https://orcid.org/0000-0003-3072-4854

E-mail: aleskrovaaleskerova@gmail.com

${ }^{2}$ Uman National University of Horticulture, Ukraine.

ORCID: https://orcid.org/0000-0002-0532-136X

E-mail: lavreniukliuba@gmail.com

${ }^{3}$ Podillia State Agricultural and Technical University, Ukraine.

ORCID: https://orcid.org/0000-0002-4685-5544

E-mail: vitagavrilyuk1@gmail.com
}

Agricultural activities face risks linked to market trends and environmental conditions, in particular, climatic conditions and in Italy, the heterogeneity of the territory determines a high variability of conditions and productions. These natural factors, associated with the scenarios of climate change, increase the level of uncertainty for agricultural activities, strongly 
influencing the interaction between climate and crops' cycles (quantity and quality of productions) and between climate and farms' investments (damages to equipment and infrastructures caused by extreme weather events). In order to manage risks in agriculture, one of the most important instruments used in the Italian agricultural sector is the insurance system that without doubts can be one of the central climate change adaptation options. In facts, agricultural insurance allows managing a wide range of risks and it is theoretically enough flexible to adapt itself to changed conditions and priorities.

However, the model of voluntary insurance with insurance subsidies remains acutely debatable. Currently, the domestic agricultural insurance system is slowly developing at the expense of formal schemes mainly in the extensive format and is accompanied by a variety of financial, informational, analytical, organizational and institutional and infrastructural issues. The problems of increasing the quality of insurance products, combining and harmonizing the interests of participants in the system of agricultural insurance, its structural modernization remain unresolved. In the present, there is a controversial process of finding its own model of development of the agricultural insurance system.

At the same time, they were closely intertwined with the remaining models of the administrative economy, as well as the latest, progressive ones. In this section, it is objectively necessary to consider the research of theoretical, methodological and practical aspects, the development on the scientific platform of strategies and a set of measures on the development of agricultural insurance system, taking into account the various instruments of state influence.

\section{Economic crisis effects on consumer behaviour}

The system of agricultural insurance as in any financial system is characterized by two driving forces - a desire to preserve itself and have some firmness and a desire to develop and modernize.

We can't but agree with $\mathrm{H}$. Visem who argued that now replacing the old ideas: "at first preservation and only then development," an increasingly established understanding: "preservation through development" since self-preservation without self-perfection and constant adaptation to the external environment leads to destructive processes and destroys the very economic system. The concept of "development" is considered rather complex in conjunction with the economic system so it is important to consider its interpretation in two formats. The first format defines development as a philosophical-scientific concept, in the second format we consider it in the cut of the economic system and more specifically in the cut of the system of agricultural insurance (Aleskerova, 2015).

In the dictionaries, it is indicated that "development is a philosophical, economic, and socio-psychological concept, the meaning of which is concentrated in irreversible, purposeful, and logical changes of material and ideal objects" (Aleskerova, 2015).

Only "simultaneous synthesis of all three properties distinguishes development among other changes" (Aleskerova, Fedoryshyna, Koval, 2018). Various interpretations of the category "development" are presented in Table 1.

Thus, the meaning of development is focused on the fact that this is a special kind of movement, which is characterizedbythreecharacteristics: quality, quantity, and

Table 1

Interpretation of the concept of "development"

\begin{tabular}{|c|c|}
\hline Author & Definition \\
\hline A. Vasilenko & The acquisition of a new quality that strengthens viability in the context of changing the environment. \\
\hline O. Shubravska & $\begin{array}{l}\text { The process of transitioning a system from one state to another, which is accompanied by a change in its qualitative and } \\
\text { quantitative characteristics. }\end{array}$ \\
\hline L. Zabrodska & $\begin{array}{l}\text { The dynamics of the transition of the economics and production system into a new more qualitative state by the } \\
\text { accumulation of quantitative potential, changes and complications of structure and composition, the echo of which is to } \\
\text { increase its ability to withstand the destructive effects of the environment and the efficiency of the activity. }\end{array}$ \\
\hline $\begin{array}{l}\text { M. Mescon, } \\
\text { M. Albert, } \\
\text { F. Khedouri }\end{array}$ & $\begin{array}{l}\text { Long-term program to improve the ability to solve various problems and ability to recover, especially by improving the } \\
\text { management of the culture of the organization. }\end{array}$ \\
\hline E. Korotkov & $\begin{array}{l}\text { The set of changes that lead to the emergence of new quality and strengthening the vitality of the system, its ability to } \\
\text { resist destructive forces of the environment }\end{array}$ \\
\hline O.V. Rayevneva & $\begin{array}{l}\text { A unique process of transformation of an open system in space and time characterized by a permanent change in the } \\
\text { global goals of its existence by forming a new dissipative structure and translating it into a new attractor of functioning. }\end{array}$ \\
\hline V. Dovbenko & $\begin{array}{l}\text { The dynamics of the state change of an object by improving its characteristics and a qualitative, quantitative increase of } \\
\text { parameters. }\end{array}$ \\
\hline M. Afanasyev & $\begin{array}{l}\text { The objective change only of the qualitative characteristics of the system is determined by the fundamental laws of nature } \\
\text { (the unity and struggle of opposites, the transfer of quantity to quality, the progress of society in a spiral and upward) } \\
\text { and the laws of the activity of specific systems (aging equipment, accumulation of experience and knowledge of workers, } \\
\text { depletion natural resources) in which the new properties of the system are formed }\end{array}$ \\
\hline
\end{tabular}


structure. Quantitative transformations are characterized by an increase or decrease in the number of components of the system or their quantitative characteristics, which after a certain time leads to qualitative transformations in accordance with the provisions of the law of transition of quantitative ones - into qualitative changes and vice versa. Structural transformations should be considered as changes in the interconnections of system components, which may not be accompanied by an increase or a decrease in their number.

Predominantly, the number of components remains unchanged but structural transformations lead to qualitative changes as internal contradictions are the driving force behind development. The process of development through internal contradictions is defined by the law of unity and the struggle of contradictions. The source of quantitative transformations is the contradiction with the external environment, the source of structural transformations is internal contradictions.

Qualitative transformations can be expressed through extrapolation: by attracting matter and energy, through interaction with the external environment and through the differentiation of the system without its deformation and imbalance or as a change in the quality of the components or subsystems of the system.

Thus, we are convinced that the development of the agricultural insurance system should be understood as the aggregate transformation of interdependencies of qualitative, quantitative, and structural characteristics. A significant influence on the level of development of the system of agricultural insurance is its design since the composition and interconnection of components of the qualitative changes and the content of the system.

\section{Differences in consumer spending behaviour among age groups}

The development of the agricultural insurance system is a complex and multi-faceted dynamic, which in a certain time interval can display progressive, regressive or stagnant characteristics, it is defined by the system of certain values and landmarks and it possesses the ability to change its composition, functions, components, subsystems.

Thus, the development of the system of agricultural insurance contributes to the development of all its components and systems of a higher order: development of insurance, development of agriculture as an industry, development of agricultural commodity producers, development of infrastructure, institutions, financial relations, innovation and investment processes, etc.

The development of the agricultural insurance system can also be outlined through the mega system of the "external environment - the system" since the agricultural insurance system is considered an open system, which has close ties and constantly interacts with external components. The set of all factors, mechanisms, preconditions should ensure the development of the system of agricultural insurance.

It is important to distinguish between "development" as a certain process and "development" as a certain result. These two linked formats are interconnected. The first format shows the directions, mechanisms, tools for achieving the goal, the other - demonstrates the effectiveness of development, the speed and completeness of achieving the goal, the formation of prerequisites for the effective development of the system. In practice, the format "development - process" acts as a platform for the format "development - result" (Aleskerova, 2018).

The basis of the development of the agricultural insurance system is the transformation: within the system and in the relationship between the system and the environment. The development of the agricultural insurance system can be due to a combination of transformations: the link between transformation and development can be considered as causal, consequential, reciprocal, interdependent, and recursive. Interestingly, the crisis and the deformation of the environment are predominantly an impetus for transformation. The key purpose is to destroy and replace the least sustainable and viable components that violate the unity of the agricultural insurance system. Crises and deformations may deepen, which is explained by unfavourable environmental events.

The above circumstances caused the relevance of this article, which aims at analysing innovative financial criteria for methodological approaches to the assessment of agrarian insurance introduction.

To achieve this purpose it is necessary to investigate innovative financial criteria for methodological approaches to assessing agricultural insurance.

\section{Survey methodology}

The methodological basis of the research is the general economic method of ascending from abstract to concrete, theoretical achievements of domestic and world financial science, conceptual provisions of modern insurance theories. The research was based on the use of a systematic approach to the consideration of financial phenomena, on the fundamental positions of economic theory, system theory, theory of finance, insurance management, etc.

Thus, the development of the agricultural insurance system is multidimensional and outlines the deep transformations in all its components. This development should take into account all interconnections and interdependencies. Therefore, in order to determine the criteria and methodological approaches to assessing the development of the agricultural insurance system, it is appropriate to consider this development in the interconnection and interdependence with other components of the environment. 
It is worth pointing out that in revealing the axioms of the complex economic systems, the thesis concerning the necessity of a criterion for the harmonious development of the system should be deepened by provisions regarding some uncertainty of this criterion and the expediency of its refinement and concretization. This provision is considered fundamental, although in its turn it causes uncertainty and risk and contributes to the construction of a qualitatively new system of agricultural insurance.

Interesting, many researchers are of the opinion that any economic system is evolving through information flows. E. Pestel noted that "uncertainty is generated when there is a lack of exhaustive exact information or there is no knowledge of the phenomenon or object of the search".

The quality in the hypostasis of the philosophical category characterizes the stable property of the phenomenon in the dynamics of its general development. That is, the quality reveals the properties of agricultural insurance, outlines its objective characteristics, essential characteristics, and functional characteristics. Without defining qualitative signs of the system of agricultural insurance, it is impossible to identify and explain the logic and trends in its development. Qualitative transformations expand and deepen the content of agricultural insurance. We can't but agree with the philosophers who claim that quality is "the primary direct determinate of being." At the same time, the quality of agricultural insurance depends on quantitative characteristics and doesn't manifest itself without them.

The number is considered an objective characteristic "indifferent in being." The number is an external property, an attribute of the phenomenon including agricultural insurance. These two characteristics (quality and quantity) don't manifest themselves without one and they are objective signs of the system of agricultural insurance. That is the criteria of development of the system of agricultural insurance; it is expedient to consider both qualitative and quantitative parameters. They are mutually interconnected; there are direct and back links and mutual influence. Quantitative transformations in agricultural insurance, which reflect its objective characteristics, appear in a certain quality circle (mention, in particular, the historical development of quantitative parameters of agricultural insurance in the cut of its qualitative characteristics).

Qualitative and quantitative characteristics of the development of the agricultural insurance system are estimated by measure. The philosophical category of measure serves as a kind of objective criterion between qualitative and quantitative indicators of agricultural insurance. The measure serves as contradictory unity, in which the qualitative characteristic is determined by quantitative (that is, quality is defined by the appropriate number) and the quantitative characteristic is determined by a qualitative (that is, the number corresponds to a certain quality).

The distortion of the measure deforms the qualitative properties of the agricultural insurance system; it changes and acquires new qualitative features. Demonstrates a qualitative outbreak or "continuity of graduality", that is, there is a jump from a certain qualitative state to another qualitative state. "Graduality" and "leap" are considered indissoluble, interconnected components of the development of agricultural insurance. The dialectical unity of these components is due to the consistency and qualitative differences between the unceasing cycles of the development of the agricultural insurance system as a complex economic phenomenon. These differences and interconnections demonstrate their echo in the evolutionary and revolutionary cycles of agricultural insurance development. In accordance with the provisions of the law of the transition of quantitative transformations to qualitative, the formation and development of the system of agricultural insurance must be carried out by gradually multiplying the quantitative components, parameters, transformations and jump to a qualitatively new level of functional transformations, from one state of the system of agricultural insurance to a qualitatively different.

Demonopolisation of domestic agricultural insurance, access to the insurance market of a large variety of private insurers explains radical qualitative changes in the system of agricultural insurance. Practically, there was a "leap" as the system of agricultural insurance began to be formed. Thus, there was a shift in quantity to quality. At the same time, the new quality of the agricultural insurance system, which is demonstrated in increasing its role in solving socio-economic problems of agricultural producers, determines the appearance of new quantitative transformations. The development of agricultural insurance requires an increase in the capitalization of insurers, in particular, through mergers, acquisitions, unions. The fall in the number of insurance companies with a simultaneous increase in insurance capital will increase the opportunities for agricultural insurance and will lead to new qualitative transformations. Such dynamics is carried out continuously. The transition of quantitative transformations into qualitative ones leads to the objective estimation of quantitative and qualitative characteristics, internal and external factors of agricultural insurance. Only by this approach, one can impartially investigate various quantitative changes in the system of agricultural insurance, explain the laws of its development, give them an objective assessment, demask their qualitative deep sense and, on this platform, ensure the formation of appropriate financial conditions for the harmonious development of the agricultural insurance system.

The development of a system of agricultural insurance is important to consider in view of the interests of the 
state, insurer, insured person since their synthesis reflects the effectiveness of the whole system.

A criterion for the development and effectiveness of the agricultural insurance system is a certain ratio of quantitative indicators and qualitative characteristics, which can be used to assess the relationship between the state, insured persons, and insurers.

The criteria for the development and efficiency of the agricultural insurance system are:

- ensuring the firmness and stability of the expanded reproduction of agricultural production;

- provision of agricultural insurance utility functions for all participants;

- coverage of insurance products by the risk maps of agricultural commodity producers;

- the fullness of damages;

- ensuring the adequacy of insurance reserves;

- quality, breadth of assortment, and profitability of insurance products;

- balance and availability of agricultural insurance;

- the efficiency of agricultural insurance;

- the rise of capitalization of insurers;

- transparency of the system of agricultural insurance.

Let's consider more carefully some of the criteria. The meaning of the coverage criterion of insurance products by the risk maps of agricultural producers is focused on providing agricultural products with insurance products for most of the identified agricultural risks. The risk map is a matrix-text description of the identified risks of agricultural commodity producers, which demonstrates the intensity of the impact, its significance, weight, and generation probability. Formation of a matrix of risk maps for agricultural producers is a laborious and time-consuming procedure. By gathering the necessary information array for systematization and generalization of agricultural risks, a significant information base is formed (Aleskerova, 2017).

The assessment of agricultural risks $(\mathrm{Q})$ is expedient to carry out by the two-factor method of Peter-Ryan: $\mathrm{Q}=\mathrm{Z}^{*} \mathrm{~J}$,

where $Q$ - the probability of adverse events; $\mathrm{J}$ - the significance of adverse events (Aleskerova, Fedoryshyna, Koval, 2018).

It is important to take parameters of the probability of adverse events at the level of average insurance rates for the selected risks. Significance is defined by the expert method. After identification of probable agricultural risks, the scenarios of their levelling or reduction and measures are selected. It is important to identify vulnerability to agricultural risk. Subsequently, mathematical information processing is carried out to identify potential losses for each identified agricultural risk and probable insurance premiums. However, the probable risks associated with the proposed range of insurance products and the level of their profitability are compared.

It is advisable to periodically update the risk map according to changes in internal factors and the external environment. The map should be improved along with the changes in agricultural production as new opportunities are generated with the expansion of opportunities, accordingly, the range of insurance products should be expanded and improved.

To analyse the provision of the insurance benefit criterion for all participants, it is advisable to apply the following algorithm:

1. The largest and smallest values of the indicator are determined, if the utility is measured on a 100-point scale, utility values are ranked from 0 to 100 .

2. Several standard values are determined, which are expertly ranked and determine utility values.

3. Average utility values are determined.

4. If there is a significant fluctuation of utility values then it is advisable to reconcile expert approaches to the range of utility values.

5. The integral utility is calculated using the regression function by calculating the least squares method.

Another key criterion for assessing the agricultural insurance system is the provision of insurance reserves. In general, insurance reserves include all components of insurance capital that can be oriented towards covering potential losses.

The search for methodological approaches to the analysis of the development of complex integrated economic systems convinces us of the inadequacy of exploiting only quantitative indicators, since they outline their state and functioning in past periods and, therefore, can't serve as a basis for predicting future development prospects. At the same time, the calculation of purely quantitative indicators will distort the assessment of the agricultural insurance system. Therefore, it is important to exuberant the system of qualitative characteristics that allows outlining the dynamics of tendencies that are not subject to mathematical estimates but they can be considered valuable for assessing the development of the system of agricultural insurance.

To assess the quality of the development of the agricultural insurance system, the list of criteria should be developed and it is important to establish the "weight" of each block of quality criteria (Todosiychuk, 2016).

The main indicator of the quality of the development of the agricultural insurance system can be the indicator $-Q$ which should be determined using the modified method of the mean square deviation, which is calculated as the difference between the values of perception and the values of expectations with the simultaneous application of weight indices. The basis for such an assessment is the weighting of each criterion block:

$$
Q=\sqrt{\sum_{i=1}^{n} k\left(a_{0}-a_{c}\right)^{2}},
$$

where $Q$ - an integral indicator of the development of the agricultural insurance system;

$i$ - criterion of quality of development of the system of agricultural insurance; 
$k$ - weight index of the relevant criterion block;

$a_{o}$ - the value of the quality of the criterion block by the level of expectation;

$n$ - the number of criteria used to assess the development of the agricultural insurance system;

$a_{c}$ - the value of the quality of the criterion unit by the level of perception.

One of the tasks of the development of the system of agricultural insurance should be the harmonization of expectations of agricultural producers with the proposed range and quality of insurance products.

To assess the balance and accessibility criteria, it is expedient to assess the regional components of the agricultural insurance system according to the following scheme:

1) on the basis of forming a set of indicators of the functioning of the agricultural insurance system for insurance products and regions, to determine correlation dependencies, a variation of coefficients and to generalize to the integrated indicator;

2) to evaluate the regional components of the agricultural insurance system using one-factor and multi-factor dependencies with the inclusion of a multivariate assessment of internal and external factors of influence.

It is expedient to search for harmonious correlation of the interests of agricultural producers, insurers, and the state with schedules of collected premiums, amounts of compensated payments, uncompensated losses, the profitability of agricultural production, loss-making of agricultural insurance and parameters of insurance subsidy ofinsurance protection of agricultural producers. Harmony of the ratio of interests will be demonstrated by the criterion of the utility of agricultural insurance and determined by the formulas:

$\mathrm{D}=\mathrm{Dmax}$, in the situation:

$\mathrm{Rrel}^{*} \mathrm{~V}=\mathrm{Z}>$ Rnorm;

$\mathrm{F}<$ Fmax;

Wnorm $=\mathrm{W}<\mathrm{Wmax}$

Where Rrel- the probability of reverse by the insured of guaranteed means higher than the standard (Rnorm);

$\mathrm{V}$ - amounts of damages to be paid to agricultural producers with a certain probability - Rrel;

$\mathrm{Z}$ - the amount of damage;

F - time slot during which losses will be recovered (Fmax);

D - the income of agricultural producers from insurance calculated as the difference between the reduction of uncompensated damages and the amounts of insurance premiums;

$\mathrm{W}$ - an integral indicator of the development of the system of agricultural insurance which includes a set of non-economic constraints harmonious balance of interests of all participants.

Integral assessment of the development of the agricultural insurance system is based on the blocks of indicators: homogeneity, balance, stability, profitability, loss-making, structuring, and risk-taking. Each block contains quantitative and high-quality parameters, coefficients, indices, indicators (Plakhtii, 2019).

Among the key indicators that should be used in the contour of the integrated assessment of the development of the agricultural insurance system, it is necessary to separate: the ratio of the amount of insurance premiums and agricultural GDP, the dynamics of the growth of assurer and insurers, the amount of insurance payments per one agricultural producer, the indicator of loss, the index of the severity of the consequences of natural disasters, the average amount of insurance indemnity, the ratio of reimbursed losses and the size of insurance premiums, the size of insurance premiums at the regional level.

The application of this integrated assessment of the development of the agricultural insurance system will make it possible to more closely identify the contour of the development of the agricultural insurance system and will serve as an information justification for the adoption of strategic decisions.

The matrix of the integrated assessment of the development of the agricultural insurance system on the platform of the modified main component has been constructed, which will facilitate the implementation of the curtailment of the output meters to form an integrated indicator and to disassociate the development of the regional components of the system (Kraybill, 1989).

A range of statistical indicators was selected that outline various aspects of the development of the agricultural insurance system and its regional components: $\tilde{X}_{1}-$ the number of insurers in general and in the regional section; $\tilde{X}_{2}$ - receipt of insurance premiums, UAH for one insured person; $\tilde{X}_{3}$ - the amount of insurance indemnities, UAH for one insured person; $\tilde{X}_{4}$ - the size of insurance premiums, UAH for one insured person; $\tilde{X}_{5}$ - segment of insurance indemnity in insurance premiums, \%, and $\tilde{X}_{6}$ - segment of insurance premiums directed to reinsurance, $\%$.

An expedient procedure for the formation of an integral indicator is the unification of the selected output data, that is, the use of extrapolation with the use of which all of them will be calculated in the N-ball format. At the same time, the zero indicator will harmonize with the smallest level of development and the maximum number $\mathrm{N}$ - with the largest. Such unification guarantees the comparability of the built information array.

\section{Findings}

Unification is carried out according to different algorithms. This is due to the expediency of unifying the components for which the ranking is from the highest to the lowest.

For measuring instruments, the rise of which contributes to increasing the measure of agricultural insurance, the index of a certain unified variable is determined by the algorithm: 


$$
x_{i j}=\frac{\tilde{x}_{i j}-\tilde{x}_{j \min }}{\tilde{x}_{j \max }-\tilde{x}_{j \min }} N
$$

Where $x_{i j}-i$ index $j$ of the output unified index $X_{j}$ ( $i=\overline{1, n}, j=\overline{1, m}, n$ - the number of observations for the index $\mathrm{Xj}, \mathrm{m}$ - the number of output values; $\tilde{x}_{i j}-i$ index $j$ output unsupported index $\tilde{X}_{j} ; \tilde{x}_{j \min }$ - the lowest index $j$ output unrestricted index $\tilde{X}_{j} ; \tilde{x}_{j \max }$ - the highest index $j$ source unregistered index $\tilde{X}_{j}$.

For meters whose rains negatively regulate the development of agricultural insurance, the index of a certain unified variable is determined by the algorithm:

$$
x_{i j}=\frac{\tilde{x}_{j \max }-\tilde{x}_{i j}}{\tilde{x}_{j \max }-\tilde{x}_{j \min }} N
$$

If the source index $\tilde{X}_{j}$ is linked to the aggregate integral index by nonmonotonic bonds (that is between $\tilde{x}_{j \min }$ and $\tilde{x}_{j \max }$ ), there is a certain optimal index $\tilde{x}_{\text {jopt }}$ at which the maximum rate of development is observed, the index of a certain unified index $\tilde{X}_{j}$ is determined by the algorithm:

$$
x_{i j o p t}=\left(1-\frac{\left|\tilde{x}_{i j}-\tilde{x}_{j o p t}\right|}{\max \left\{\left(\tilde{x}_{j \max }-\tilde{x}_{j o p t}\right),\left(\tilde{x}_{j o p t}-\tilde{x}_{j \min }\right)\right\}}\right) N
$$

The definition of the integrated indicator $\mathrm{Y}$ is calculated by the algorithm:

$$
Y=\sum_{j=1}^{m} w_{j} X_{j} \text {, }
$$

where $w_{j}$ - weight index, $X_{j}$ - output values, $m-$ the number of output values.

According to the definition of the modified main component by the algorithm (5) as a weight $w_{j}$ it is expedient to take the squares of the component $j$ in a certain trajectory $l_{1}$ of the matrix of the measuring instruments $X_{1}, X_{2}, \ldots, X_{m}$.

When forming an integral indicator of the development of the agricultural insurance system in the country and in the regional section according to the algorithm (2.21), for comparison, weight indices $w_{j}$ were calculated at the same time according to another algorithm, namely, the dispersion segment $\mathrm{D}(\mathrm{Xj})$ of the value of $X_{j}$ in the totality of the dispersion of all output indices:

$$
w_{j}=\frac{D\left(X_{j}\right)}{\sum_{j=1}^{m} D\left(X_{j}\right)} \text {. }
$$

The purpose of this assessment is to disassociate the laws and strategies of the development of the agricultural insurance system.

Such an assessment helps identify trends in the development of the agricultural insurance system and outlines the weaknesses of the system. The platform of the proposed methodological approach to assessing the development of the agricultural insurance system is a set of criterion characteristics and a balanced synthesis of selected meters (Schindler, 1994).

\section{Conclusions}

Insurance agricultural risk is defined as possible damage inflicted on a particular object of insurance due to its loss or damage as a result of the insured event specified in the insurance contract, calculated in the value equivalent but not greater than the specified amount of insurance. Such an interpretation of insurance agricultural risks has allowed developing a matrix of insurance and non-insurance agricultural risks that are inherent in agricultural production.

Methods of calculating the insurance premium for agricultural insurance require reliable, objective, longterm data, which is possible when a system for collecting and processing statistical information on insurance incidents in agriculture is established (Aleskerova, 2015).

Nowadays, agricultural insurance procedures and technologies can't be considered perfect because of the inadequate exploitation of progressive tools.

The mechanism of agricultural insurance - is the construction of methods, instruments, tools, and appropriate support. In this context, it is advisable to allocate the following components of the mechanism of agricultural insurance:

1) subjects and objects of agricultural insurance;

2) methods, levers, and instruments;

3) income, expenses, and reserves;

4) institutional and infrastructure component;

5) informational and organizational support.

Components of the mechanism of agricultural insurance with varying intensity affect the development of both the system of agricultural insurance and its participants (Ransom, 2011).

The development of the agricultural insurance system is a complex and multi-faceted dynamic, which in a certain time interval can display progressive, regressive or stagnant characteristics, it is defined by the system of certain values and landmarks and it possesses the ability to change its composition, functions, components, subsystems.

The matrix of the integrated assessment of the development of the agricultural insurance system on the platform of the modified main component has been constructed, which will facilitate the implementation of the curtailment of the output meters to form an integrated indicator and to disassociate the development of the regional components of the system.

\section{References:}

Aleskerova, Yu., Mulyk, T., \& Fedoryshyna L. (2018). Improving credit protection analysis methods Reports of main agricultural enterprises. Baltic Journal of Economic Studies, 4(2), 1-7. doi: 10.30525/2256-0742/2018-4-2-1-7 Aleskerova, Yu., \& Fedoryshyna, L. (2018). Analysis of investment activities of enterprises of Ukraine. Economic system development trends: the experience of countries of Eastern Europe and prospects of Ukraine: monograph. Riga, Latvia: "Baltija Publishing”. 
Aleskerova, Yu., Fedoryshyna, L., \& Koval, N. (2018). Features of loan security for the reproduction of fixed assets for agricultural purposes. Baltic Journal of Economic Studies, 4(4), 1-5. doi: 10.30525/2256-0742/2018-4-4-1-5

Aleskerova, Y. V. (2014). Governmental support to agricultural insurance in the countries of the world. Economic Sciences: theory and practice. Baku: Azerbaijan State University of Economics, 71(2), 31-41.

Plakhtii, T., Fedoryshyna, L., \& Tomchuk, O. (2019). Socio-economic component of preferential taxation of individuals' incomes. Baltic Journal of Economic Studies, 5(2), 1-7.

Aleskerova, Yu., \& Todosiychuk, V. (2016). Fiscal multipliers in Ukraine. Economy and management organization, 4(24), $36-43$.

David Ransom (2011). IF1 - Insurance, Legal \& Regulatory. Chartered Insurance Institute.

Donald, B. Kraybill (1989). The riddle of Amish culture.

Schindler, R. M. (1994). Consumer Motivation for Purchasing Low-Deductible Insurance. In Marketing and Public Policy Conference Proceedings, 4, 147-155. 